\title{
(E) \\ Spectroelectrochemistry of Vanadium Acetylacetonate and Chromium Acetylacetonate for Symmetric Nonaqueous Flow Batteries
}

\author{
James D. Saraidaridis, ${ }^{\mathrm{a}, *}$ Bart M. Bartlett, ${ }^{\mathrm{b}}$ and Charles W. Monroe ${ }^{\mathrm{a}, * *, \mathrm{z}}$ \\ ${ }^{a}$ Department of Engineering Science, University of Oxford, Oxford OX1 3PJ, United Kingdom \\ ${ }^{b}$ Department of Chemistry, University of Michigan, Ann Arbor, Michigan 48109, USA
}

\begin{abstract}
Chromium acetylacetonate, or $\mathrm{Cr}(\mathrm{acac})_{3}$, is a promising active species for high-energy-density symmetric redox flow batteries because the neutral complex supports multiple charge-transfer reactions with widely separated redox potentials. Voltammetric and spectroelectrochemical measurements were performed to probe the mechanism of the first electrochemical disproportionation of $\mathrm{Cr}(\mathrm{acac})_{3}$ - i.e., the cell reaction associated with the two redox couples immediately adjacent to the equilibrium potential of a freshly prepared nonaqueous $\operatorname{Cr}(\mathrm{acac})_{3}$ solution. Substantially different limiting currents are observed for the positive and negative half-reactions, suggesting that at least one deviates from the similar outer-sphere single-electron transfer mechanisms proposed earlier. Spectroelectrochemical chronoamperometry suggests ligand dissociation in the negative reaction, and consequent structural reorganization of the $\mathrm{Cr}(\mathrm{acac})_{3}$ complex. Vanadium acetylacetonate was investigated for comparison, and no ligand dissociation was observed. A negative half-reaction mechanism consistent with the voltammetric and spectroelectrochemical data is proposed, and used to rationalize observations of charge/discharge behavior in cycling $\mathrm{Cr}(\mathrm{acac})_{3}$ cells.

(c) The Author(s) 2016. Published by ECS. This is an open access article distributed under the terms of the Creative Commons Attribution Non-Commercial No Derivatives 4.0 License (CC BY-NC-ND, http://creativecommons.org/licenses/by-nc-nd/4.0/), which permits non-commercial reuse, distribution, and reproduction in any medium, provided the original work is not changed in any way and is properly cited. For permission for commercial reuse, please email: oa@electrochem.org. [DOI: 10.1149/2.0441607jes] All rights reserved.
\end{abstract}

Manuscript submitted February 11, 2016; revised manuscript received March 31, 2016. Published April 15, 2016.

As researchers have identified the economic benefits that largescale energy storage delivers to the grid, research into redox flow batteries (RFBs) has expanded. ${ }^{1}$ In efforts to increase energy density or decrease active-species loading, researchers have targeted nonaqueous RFB chemistries, which can produce operating potentials outside the stability window of water. ${ }^{2-8}$ Several nonaqueous chemistries are based on transition-metal-centered coordination complexes. ${ }^{2,3,6-9}$

Chromium acetylacetonate, or $\mathrm{Cr}(\mathrm{acac})_{3}$, appears especially promising as an RFB active species: it has five accessible redox states, and there is a wide voltage separation between the first reduced and first oxidized states of the neutral complex. The $\mathrm{Cr}(\mathrm{acac})_{3}$ complex has also been used for catalysis ${ }^{10}$ and as a standard for atomic absorption spectra. ${ }^{11}$ Whereas vanadium acetylacetonate, or $\mathrm{V}(\mathrm{acac})_{3}$, appears to support outer-sphere electron transfer for both single-electron addition and withdrawal in certain nonaqueous electrolytes, and to undergo both charge exchanges with relatively facile kinetics, ${ }^{12}$ the voltammetric response of $\mathrm{Cr}(\mathrm{acac})_{3}$ is harder to interpret. Experimental efforts to clarify the electrochemistry of $\mathrm{Cr}(\mathrm{acac})_{3}$ have been challenging because the reaction mechanism apparently varies with the choices of solvent, supporting electrolyte, and working electrode. ${ }^{13-17}$

The literature describing nonaqueous $\mathrm{Cr}(\mathrm{acac})_{3}$ electrochemistry does not provide a consensus about the mechanisms for either the first reduction or first oxidation of the neutral complex. The electrochemical response during reduction depends heavily upon solvent, with different behavior observed in dimethylsulfoxide, ${ }^{13,15,18,19}$ $\mathrm{N}, \mathrm{N}$-dimethylformamide, ${ }^{15}$ dichloromethane, ${ }^{14}$ acetonitrile, ${ }^{15,17,20}$ and others. ${ }^{15}$ Various mechanisms have been proposed for the first reduction, but the first oxidation mechanism has only received significant attention since $\mathrm{Cr}(\mathrm{acac})_{3}$ was proposed for nonaqueous RFB applications. $^{3,21}$

Most reports of $\mathrm{Cr}(\mathrm{acac})_{3}$ electrochemistry describe experiments performed with $\mathrm{Hg}$ electrodes, which have been observed to form complexes with $\mathrm{acac}^{-}$ions. ${ }^{22}$ When the nonaqueous electrochemistry of $\mathrm{Cr}(\mathrm{acac})_{3}$ was compared between $\mathrm{Hg}$ and $\mathrm{Pt}$ working electrodes, experiments using $\mathrm{Hg}$ suggested the presence of three distinct reduction events, whereas those with Pt only indicated one. ${ }^{17}$ The $\mathrm{Cr}(\mathrm{acac})_{3}$ complex oxidizes at relatively high potentials, which have only been

\footnotetext{
*Electrochemical Society Student Member.

***Electrochemical Society Member.

${ }^{\mathrm{z}}$ E-mail: charles.monroe@eng.ox.ac.uk
}

probed with solid electrodes because they are beyond the oxidation potential of $\mathrm{Hg} .{ }^{3,21}$

The choice of supporting electrolyte is also known to affect the electrochemical behavior of $\beta$-diketonate coordination complexes. When supported by alkali and alkaline-earth-metal salts, the cations coordinate with $\mathrm{acac}^{-}$ligands harvested from the $\mathrm{M}(\mathrm{acac})_{3}$ and shift equilibrium reduction potentials; this coordination does not occur in the presence of tetraethylammonium cations, however. ${ }^{16,23,24}$ Tetraalkylammonium salts have consequently been preferred as supporting electrolytes for nonaqueous RFB research.

Nonaqueous RFB cells based on several metal/organic coordination complexes have been hypothesized to charge and discharge via single-electron disproportionation and comproportionation mechanisms, respectively, ${ }^{2,3,6,8,9}$ but the chromium system exhibits unexpected charge/discharge behavior in light of this proposed electrochemistry. The present study aims to illuminate the chemical or electrochemical processes responsible for the unusual cycling responses of $\mathrm{Cr}(\mathrm{acac})_{3}$ cells.

Linear-sweep voltammetry (LSV) experiments with microelectrodes, similar to those performed by Shinkle et al. ${ }^{12}$ with $\mathrm{V}(\mathrm{acac})_{3}$ solutions, show that the redox activity of $\mathrm{Cr}(\mathrm{acac})_{3}$ is inconsistent with a single-electron disproportionation mechanism: there appears to be a charge imbalance between the first oxidation and the first reduction half-reactions. Spectroelectrochemistry supports the previously proposed simple outer-sphere mechanism for $\mathrm{V}(\mathrm{acac})_{3}$, while experiments with $\mathrm{Cr}(\mathrm{acac})_{3}$ provide evidence of ligand dissociation during the first reduction.

A new mechanism for $\mathrm{Cr}(\mathrm{acac})_{3}$ reduction is proposed that is consistent with the voltammetric and spectroelectrochemical observations. The alternative mechanism suggests a different overall cell reaction for RFBs involving $\mathrm{Cr}(\mathrm{acac})_{3}$, which can affect expectations for charge/discharge performance and solution metrics such as theoretical maximum energy density. Clarification of the reduction mechanism could inform the uses of $\mathrm{Cr}(\mathrm{acac})_{3}$ as an electrocatalyst or standard as well.

\section{Experimental}

Chromium acetylacetonate (99.99\%, Sigma-Aldrich, USA), acetylacetone (H(acac), 99\%, Sigma-Aldrich, USA), and vanadium acetylacetonate $(98 \%$, Strem Chemicals, USA) were used as delivered. 


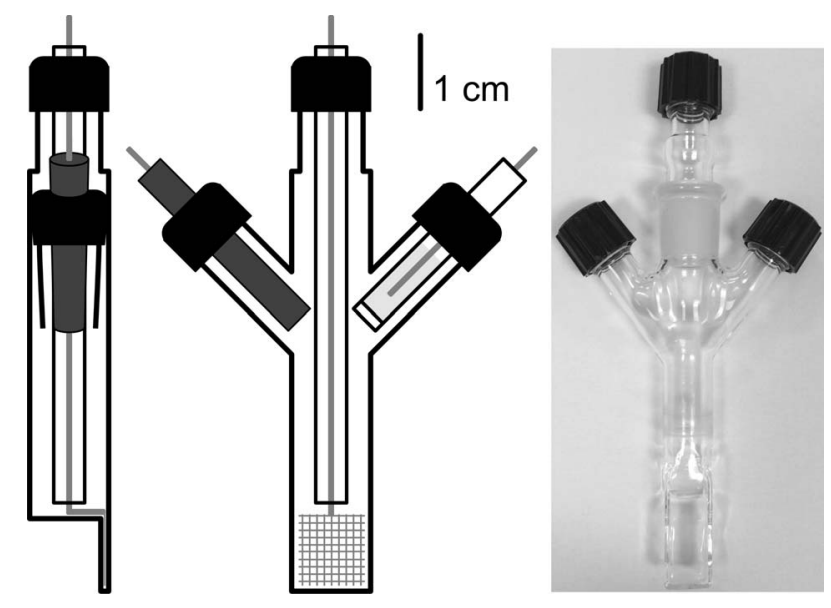

Figure 1. Schematic diagram and photograph of the spectroelectrochemical cell.

Tetraethylammonium tetrafluoroborate $\left(\mathrm{TEABF}_{4}, 99 \%\right.$, Alfa Aesar, USA) was recrystallized in methanol following the procedure of Rolfe et al. ${ }^{25}$ and dried under a nitrogen atmosphere. All solutions were prepared in an argon-filled glove box (OMNI series, Vacuum Atmospheres, USA) with oxygen and water contents under $1 \mathrm{ppm}$. Anhydrous acetonitrile (99.8\%, Sigma-Aldrich, USA) was dried over molecular sieves in the glove box for more than 24 hours before being used to prepare solutions.

Metal microelectrodes for voltammetry were fabricated by encapsulating platinum wires $(99.9 \%, 100 \mu \mathrm{m}$ diameter, Alfa Aesar, USA) in molten soda-lime-glass tubing, then grinding the ends after cooling to expose the metal surface. Electrode areas were verified using voltammetry in aqueous potassium ferricyanide solutions, as described by Kucernak et al. ${ }^{26}$

LSV was performed using three-electrode electrochemical cells in the glove box, which were connected to an Autolab PGStat 302N potentiostat (Metrohm, USA) via electrical feed-throughs in the glove box wall. Experiments were performed in a three-chamber cell with the counter, reference, and working electrodes in separate chambers. All working electrodes were polished wet with alumina slurry $(5 \mu \mathrm{m}$, then $0.05 \mu \mathrm{m}$, Pine Instruments, USA) and dried between experiments. A coiled $0.3 \mathrm{~m}$ length of Pt wire $(99.99 \%, 0.5 \mathrm{~mm}$ diameter, Alfa Aesar USA) was used as the counter electrode in all cases. Voltammetry was performed relative to a nonaqueous $\mathrm{Ag} / \mathrm{Ag}^{+}$reference electrode (BASi Inc., USA) comprising a silver wire submersed in a solution of $0.01 \mathrm{M} \mathrm{AgNO} 3(99 \%$, BASi Inc., USA) and $0.1 \mathrm{M}$ $\mathrm{TEAClO}_{4}(90 \%$, Alfa Aesar, USA) in acetonitrile (ACN). The reference electrode was ionically connected with the working solution through a fritted junction involving an intervening solution of $0.05 \mathrm{M}$ $\mathrm{TEANO}_{3}(97 \%$, Fluka, USA) in ACN. After running an LSV experiment in the negative (for reduction) or positive (for oxidation) direction away from a potential of $0 \mathrm{~V}$ vs. $\mathrm{Ag} / \mathrm{Ag}^{+}$, the voltage was swept back across the same range, but in the reverse direction, to look for hysteresis in the current response. All linear-sweep voltammograms showed minimal hysteresis; results presented graphically below show both the forward and reverse voltage sweeps for every experiment.

Spectroelectrochemical experiments were performed in a custom cell, which was fabricated in-house and is depicted in Figure 1. A 1-mm pathlength quartz cuvette was fused to an airtight glass cell body via a quartz/glass gradient. A Pt-mesh working electrode accessed the electrolytic solution occupying the quartz cuvette while a Ptdisc ( $3 \mathrm{~mm}$ diameter) counter electrode completed the circuit from a sidearm in the glass cell body. Another sidearm allowed access for the nonaqueous $\mathrm{Ag} / \mathrm{Ag}^{+}$reference electrode. To clean the Pt mesh, it was rinsed with ultrapure water, subsequently rinsed with acetone, and dried; the Pt disc was cleaned using the aforementioned polishing procedure.
Chronoamperometric electrolysis was performed using an $\mathrm{Ag} / \mathrm{Ag}^{+}$ reference electrode containing a solution of $0.01 \mathrm{M} \mathrm{AgNO}_{3}$ and 0.1 $\mathrm{M} \mathrm{TEAClO}_{4}$ in $\mathrm{ACN}$. The spectroelectrochemical cell was assembled and filled with the test solution in the glove box; the electrode ports were then sealed using screw tops containing o-rings before being transferred out of the glove box and into a spectrophotometer for experiments. Prior to beginning chronoamperometry, a cyclic voltammogram was collected to determine the suitable range of applied potentials. Spectra were gathered using ThermoFisher Genesys $10 \mathrm{~S}$ UV-Vis (Fisher, USA) and Cary 40 (Agilent, USA) spectrophotometers to quantify UV-visible and near-infrared absorption, respectively. The general procedure involved observing the absorbance spectrum of the pristine solution at its open-circuit potential (OCP), followed by collection of spectra after applied chronoamperometric electrolysis for $30,60,120,240$, and 480-second intervals. Unless otherwise specified, the spectra reported here illustrate absorbance data collected after the last electrolysis interval (after 930 total seconds of applied potential). A baseline spectrum obtained from a $0.025 \mathrm{M}$ solution of $\mathrm{TEABF}_{4}$ in $\mathrm{ACN}$ has been subtracted from all the data reported here to isolate effects due to other solutes.

Charge-discharge experiments were performed in a two-chamber, $10 \mathrm{~cm}$ long cylindrical glass cell, similar to the one described earlier by Shinkle et al. ${ }^{27}$ Electrolytic solutions were contained within two $12.5 \mathrm{~mL}$ chambers, which were continuously stirred by Teflon-coated magnetic stir-bars. A Celgard 4560 membrane was used to separate the positive and negative cell chambers. The separator was rinsed with ACN before use and allowed to soak within the loaded cell for 24 hours before beginning experiments. The electrodes employed in the charge/discharge experiments were graphite slabs (GraphiteStore, U.S.), offering $2.54 \mathrm{~cm}^{2}$ of contact surface to each solution. Galvanostatic charge/discharge experiments were performed using a solution of $0.05 \mathrm{M} \mathrm{Cr}(\mathrm{acac})_{3}$ and $0.5 \mathrm{M} \mathrm{TEABF}_{4}$ in $\mathrm{ACN}$. The charge/discharge scheme entailed a $0.39 \mathrm{mAcm}^{-2}$ charging current density to deliver $30 \%$ of the theoretical maximum state of charge (SOC) assuming 1electron disproportionation or $4.1 \mathrm{~V}$ - whichever came first - and a $0.039 \mathrm{mAcm}^{-2}$ discharging current density down to a $0.5 \mathrm{~V}$ cutoff. All charge/discharge experiments were performed in the argon-filled glove box.

\section{Voltammetry Results}

Whereas $\mathrm{V}(\mathrm{acac})_{3}$ displays facile electrochemical kinetics for both oxidation and reduction, ${ }^{2,12}$ redox of $\mathrm{Cr}(\mathrm{acac})_{3}$ is apparently less reversible, as the cyclic voltammogram presented in Figure 2 confirms.

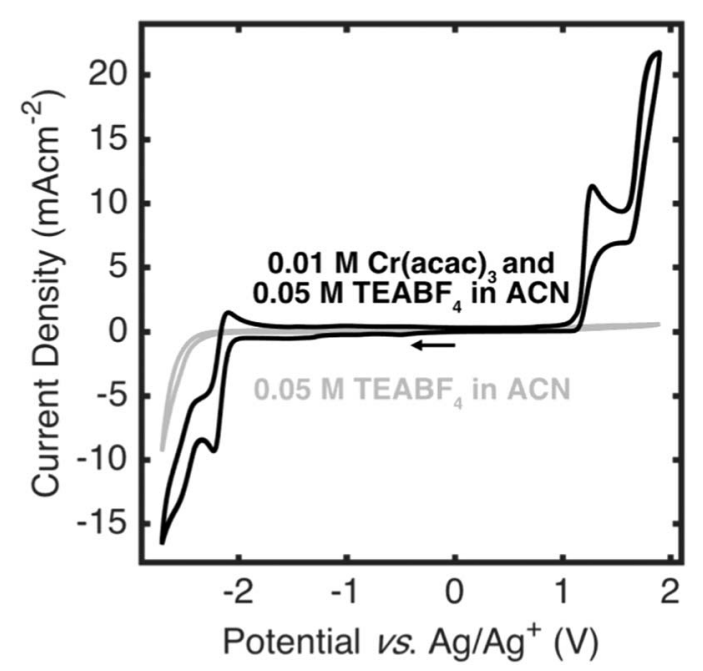

Figure 2. Cyclic voltammograms of $\mathrm{Cr}(\mathrm{acac})_{3}$ in supporting electrolyte (black) and supporting electrolyte alone (gray): $500 \mathrm{mVs}^{-1}$ scan rate, Pt working electrode, $299 \mathrm{~K}$, Ar atmosphere. 
(A cyclic voltammogram of $\mathrm{TEABF}_{4}$-supported $\mathrm{V}(\mathrm{acac})_{3}$ in acetonitrile has been reported previously by Shinkle et al. ${ }^{27}$ ) For the halfreaction centered around $1.2 \mathrm{~V}$ vs. $\mathrm{Ag} / \mathrm{Ag}^{+}$, no significant reduction peak is visible, whereas the corresponding oxidation peak is sharply defined. In an effort to clarify the cyclic voltammetry, LSV was performed using disk microelectrodes at a sweep rate of $1 \mathrm{mVs}^{-1}$. Use of microelectrodes makes diffusion transients very short, so that liquidphase mass transport can be taken to reside in a pseudo-steady state at all times. An ancillary benefit of the small electrode area is that the overall conversion of the active species is small during a voltage sweep, so solution properties change minimally over the course of an experiment.

Microelectrode LSV data for $\mathrm{V}(\mathrm{acac})_{3}$ was gathered in the past by Shinkle et al., who used it to determine kinetic parameters such as exchange-current density and symmetry factor for the two redox couples flanking the OCP of freshly prepared $\mathrm{TEABF}_{4}$-supported $\mathrm{V}(\mathrm{acac})_{3}$ solutions in acetonitrile. ${ }^{12}$ The model from that study is based on an assumption that the metal complex undergoes an outersphere, single-electron disproportionation, i.e., it identifies the redox events on either side of the OCP with a $\left[\mathrm{V}(\mathrm{acac})_{3}\right]^{0 /+1}$ couple (at $0.45 \mathrm{~V}$ vs. $\left.\mathrm{Ag} / \mathrm{Ag}^{+}\right)$and a $\left[\mathrm{V}(\mathrm{acac})_{3}\right]^{-1 / 0}$ couple (at $\left.-1.77 \mathrm{~V} \mathrm{Vs.} \mathrm{Ag} / \mathrm{Ag}^{+}\right)$.

As discussed by Shinkle et al., ${ }^{12}$ the microelectrode LSV response of a complex that disproportionates electrochemically differs from traditional LSV experiments that probe isolated half-reactions. During microelectrode LSV of disproportionation complexes, current is expected to be near zero at the OCP of the pristine solution, and nonzero currents are observed at the equilibrium potentials of the positive and negative couples involved in the disproportionation. Generally the current falls (or rises) to a negative (positive) limiting current as the potential traverses past the first redox couple below (above) the OCP. If the pristine complex is the limiting reactant and the number of electrons involved is identical in both the positive and negative half-reactions, then the limiting currents achieved at low and high potentials during LSV are expected to be equal and opposite. Consistent with the hypothesized outer-sphere single-electron electrochemical disproportionation, microelectrode LSV experiments with solutions of $0.01 \mathrm{M} \mathrm{V}(\mathrm{acac})_{3}$ and $0.05 \mathrm{M} \mathrm{TEABF}_{4}$ in ACN exhibited approximately equal and opposite limiting currents for the first positive and negative couples adjacent to the OCP of the pristine solution.

Reduction and oxidation LSV data for solutions of $0.01 \mathrm{M}$ $\mathrm{Cr}(\mathrm{acac})_{3}$ supported by $0.05 \mathrm{M} \mathrm{TEABF}_{4}$ in $\mathrm{ACN}$ are shown in Figure 3 . Figures $3 \mathrm{a}$ and $3 \mathrm{~b}$ each present three voltammograms of freshly prepared solutions using three different platinum microelectrodes in independent experiments. The $\mathrm{Cr}(\mathrm{acac})_{3}$ voltammograms are nonhysteretic and show appreciable currents at the equilibrium potentials of both the first negative and first positive redox couples, at $-2.17 \mathrm{~V}$ and $1.20 \mathrm{~V}$ vs. $\mathrm{Ag} / \mathrm{Ag}+$, respectively. The current reaches a limiting value of $i_{\mathrm{L}}^{-}=-4.2 \mathrm{mAcm}^{-2}$ when sweeping past the first negative couple and $i_{\mathrm{L}}^{+}=6.3 \mathrm{mAcm}^{-2}$ when sweeping past the first positive couple. Instead of the similar magnitudes one would expect based on the $\mathrm{V}(\mathrm{acac})_{3}$ electrochemistry, ${ }^{3}$ these limiting currents differ substantially, having an approximately $2: 3$ ratio $(4.2 / 6.3=0.67)$ between the first negative and first positive couple.

On the basis that tetraethylammonium salts have been observed to be passive in other $\mathrm{M}(\mathrm{acac})_{3}$ redox reactions, ${ }^{16,23,24}$ it is appropriate to work under the assumption that the neutral complex is the only solution-phase reactant when it first oxidizes or reduces. In that case general reaction mechanisms can be proposed for the first negative and first positive couples,

$$
a \mathrm{Cr}(\mathrm{acac})_{3}+b \mathrm{e}^{-} \rightleftharpoons \text { reduction products }
$$

$$
c \mathrm{Cr}(\mathrm{acac})_{3} \rightleftharpoons \text { oxidation products }+d \mathrm{e}^{-}
$$

where $a, b, c$, and $d$ are positive integers. Since the reacting molecule is the same in both half-reactions, the maximum diffusion-limited reactant fluxes have the same magnitudes. Thus the limiting currents
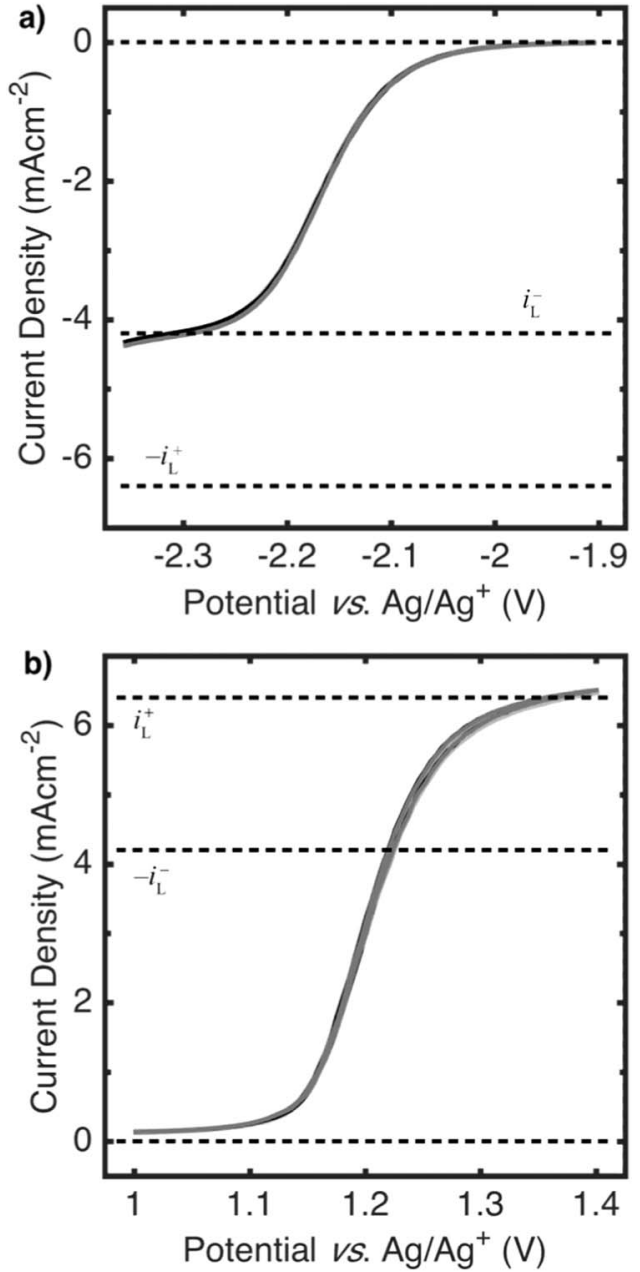

Figure 3. Linear-sweep voltammograms at $1 \mathrm{mVs}^{-1}$ probing a) the first reduction and b) the first oxidation of $0.01 \mathrm{M} \mathrm{Cr}(\mathrm{acac})_{3}$ and $0.05 \mathrm{M} \mathrm{TEABF}_{4}$ in $\mathrm{ACN}$ on Pt at $299 \mathrm{~K}$ under an Ar atmosphere. Each panel presents three data sets; each data set includes both a forward and reverse voltage sweep. Horizontal dashed lines indicate zero current, as well as the magnitudes of limiting currents, which are labeled $i_{\mathrm{L}}^{+}$and $i_{\mathrm{L}}^{-}$.

relate through the stoichiometric constants in Reactions 1 and 2,

$$
\frac{c}{d}\left|i_{\mathrm{L}}^{+}\right|=\frac{a}{b}\left|i_{\mathrm{L}}^{-}\right|, \text {or } \frac{\left|i_{\mathrm{L}}^{-}\right|}{\left|i_{\mathrm{L}}^{+}\right|}=\frac{b c}{a d} .
$$

Given the observation that $\left|i_{\mathrm{L}}^{-}\right|=\frac{2}{3}\left|i_{\mathrm{L}}^{+}\right|$, this constraint affords four possibilities for the half-reaction stoichiometries: $a=b$ and $c / d=2 / 3$; $a=c$ and $b / d=2 / 3 ; c=d$ and $b / a=2 / 3$; or $b=d$ and $c / a=2 / 3$.

One mechanism consistent with the observed limiting currents and perhaps the simplest - is a disproportionation in which both the reduction and oxidation involve the exchange of multiple electrons with a single $\operatorname{Cr}(\mathrm{acac})_{3}$ molecule $(a=c=1, b=2$, and $d=3)$. This would entail reducing a $\mathrm{Cr}[\mathrm{III}]$ complex to $\mathrm{Cr}[\mathrm{I}]$ while oxidizing another $\mathrm{Cr}[\mathrm{III}]$ complex to $\mathrm{Cr}[\mathrm{VI}]$, which is unlikely: examinations of the first reduction of $\mathrm{Cr}(\mathrm{acac})_{3}$ on various electrodes and in various supporting solutions have not yielded any reports of multiple-electron first reductions. ${ }^{13,15,17-20}$ Additionally, a mechanism where the $\mathrm{Cr}[\mathrm{III}]$ complex oxidized to $\mathrm{Cr}[\mathrm{VI}]$ would be anomalous in light of the responses of other $\mathrm{M}(\mathrm{acac})_{3}$ complexes, which appear consistent with single-electron oxidations. ${ }^{2,9,28}$

Both dimerization of the complex or the chromium within it and ligand-dissociation processes allow mechanisms consistent with Equation 3 in which $b / d \neq 2 / 3$. UV-visible/near-IR spectrophotometry was used to explore these possibilities. 


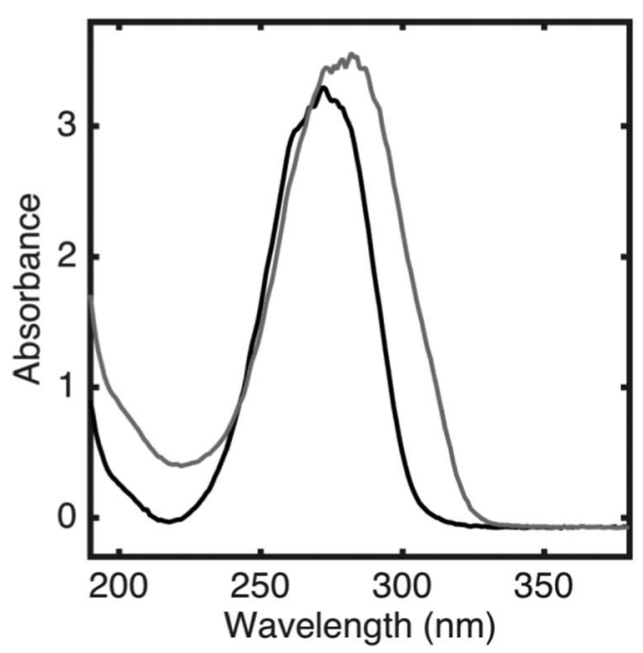

Figure 4. UV spectrogram of $0.003 \mathrm{M}$ acetylacetone and $0.025 \mathrm{M} \mathrm{TEABF}_{4}$, in $\mathrm{ACN}$ before (black) and after (gray) chronoamperometric reduction at -2.4 $\mathrm{V}$ vs. $\mathrm{Ag} / \mathrm{Ag}^{+}$for 450 seconds.

\section{Spectroelectrochemistry Results}

The spectroelectrochemical cell was first used to probe the hypothesis that the products in Reactions 1 and 2 involve species with bonds between two chromium atoms. Literature regarding other transition-metal dimers suggests that absorption signatures of dimerization would be expected in the near infrared. ${ }^{29,30}$ Solutions with active-species concentrations ranging from $0.001 \mathrm{M}$ to $0.05 \mathrm{M}$ were electrolyzed chronoamperometrically at -2.4 and $1.5 \mathrm{~V}$ vs. $\mathrm{Ag} / \mathrm{Ag}^{+}$ following the procedure described in the Experimental section. No changes in absorbance were observed in the 1000-3500 nm IR spectrum; chromium dimerization was therefore excluded as a possibility in further study.

An alternative series of spectroelectrochemical experiments was executed to assess the possibility of ligand dissociation. Several reports have suggested that ligand dissociation may be involved in the electrochemical response of $\mathrm{Cr}(\mathrm{acac})_{3}$ redox couples. ${ }^{3,15,21,31}$ Spectroscopic signatures of acetylacetonate were collected from a solution of $0.003 \mathrm{M}$ acetylacetone - abbreviated as $\mathrm{H}(\mathrm{acac})$ - and 0.025 $\mathrm{M} \mathrm{TEABF}_{4}$ in acetonitrile by electrochemically inducing hydrogen evolution on the spectroelectrochemical cell's platinum working electrode. That is, an applied potential was used to drive electrolysis, shifting the $\mathrm{H}(\mathrm{acac}) /(\mathrm{acac})^{-}$equilibrium according to the cell reaction

$$
\mathrm{H}(\mathrm{acac}) \rightleftharpoons \mathrm{H}^{+}+(\mathrm{acac})^{-},
$$

which follows from the two half-reactions ${ }^{32}$

$$
\begin{gathered}
2 \mathrm{H}^{+}+2 \mathrm{e}^{-} \rightleftharpoons \mathrm{H}_{2} \\
2 \mathrm{H}(\mathrm{acac})+2 \mathrm{e}^{-} \rightleftharpoons \mathrm{H}_{2}+2(\mathrm{acac})^{-} .
\end{gathered}
$$

As Figure 4 shows, absorption associated with (acac) $)^{-}$is centered in the UV region around $290 \mathrm{~nm}$, whereas H(acac) absorbs near $270 \mathrm{~nm}$. Additionally, bubble formation was observed at the platinum working electrode when held at reducing potentials, consistent with the hypothesis that $\mathrm{H}_{2}$ gas is evolved by the electrolysis. Even at the low concentrations used for the experiment, absorbance at some wavelengths reached the maximum measurable limits of the spectrophotometer ( $>3$ ): the detection of $\mathrm{H}(\mathrm{acac})$ absorption appears saturated from 260 $280 \mathrm{~nm}$, while acac ${ }^{-}$detection appears saturated from 275-295 nm. Despite the saturation, the absorbance wavelengths are consistent with previous literature regarding the electrochemical formation and UV analysis of (acac) $)^{-32-34}$

Solutions of $\mathrm{V}(\mathrm{acac})_{3}$ or $\mathrm{Cr}(\mathrm{acac})_{3}$ supported by $0.025 \mathrm{M} \mathrm{TEABF}_{4}$ in acetonitrile were subjected to chronoamperometric electrolysis to
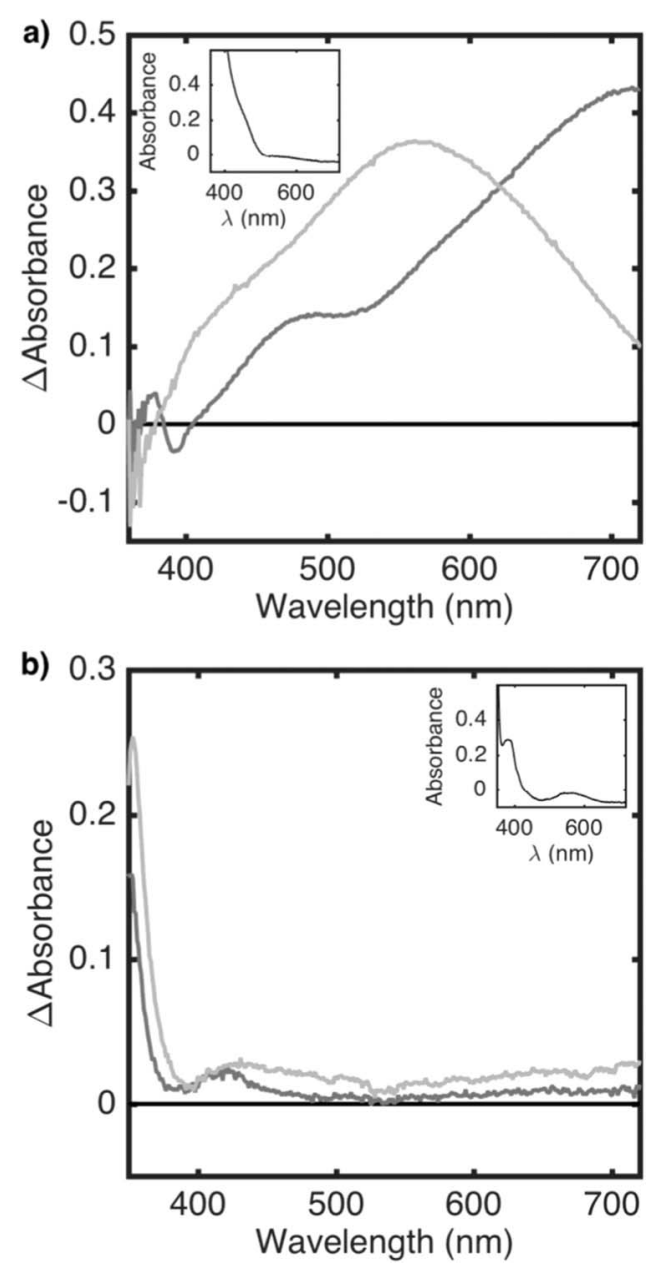

Figure 5. Change in absorbance of $0.005 \mathrm{M} \mathrm{a}) \mathrm{V}(\mathrm{acac})_{3}$ and b) $\mathrm{Cr}(\mathrm{acac})_{3}$ in $0.025 \mathrm{M} \mathrm{TEABF}_{4}$-supported $\mathrm{ACN}$ upon reduction (light gray) and oxidation (dark gray). The inset shows a baseline absorbance spectrum collected before the application of potential.

illustrate how the absorbance varies during the first reduction or oxidation of the pristine complexes. Experiments with $0.005 \mathrm{M}$ activespecies concentrations in the support, shown in Figure 5, revealed absorbance shifts in the visible spectrum, which were consistent with the perceptible color changes observed for both solutions as electrolysis progressed. Brown solutions of vanadium species reduced to black and oxidized to blue, whereas violet solutions of chromium species reduced and oxidized to deeper violet colors.

The absorption peak associated with the vanadium center, whose spectroscopic behavior is known to vary substantially with charge state in aqueous solutions, ${ }^{35}$ shows significantly larger changes in visible absorbance with the duration of applied potential than the chromium solution does. For the pristine solutions of neutral complexes, both visible absorbance profiles were found to be consistent with those reported in literature. ${ }^{34,36}$ Experiments with $0.001 \mathrm{M}$ solutions allowed spectroscopic behavior in the UV region to be analyzed, providing insight into ligand dissociation.

Change in the absorbance of $\mathrm{V}(\mathrm{acac})_{3}$ in the UV spectrum is illustrated in Figure 6. There is a strong absorbance plateau centered at 285 $\mathrm{nm}$ for the neutral complex, which is associated with the coordinated acac moiety, and the absorbance shifts little after either electrolysis. Since there are no significant increases in absorbance in the free $\mathrm{acac}^{-}$ region of the spectrum, $\mathrm{V}(\mathrm{acac})_{3}$ yields little evidence of ligand dissociation. This observation is consistent with previous hypotheses: ${ }^{27}$ the reaction mechanisms for both the positive and negative couples associated with $\mathrm{V}(\mathrm{acac})_{3}$ are probably simple outer-sphere single-electron 


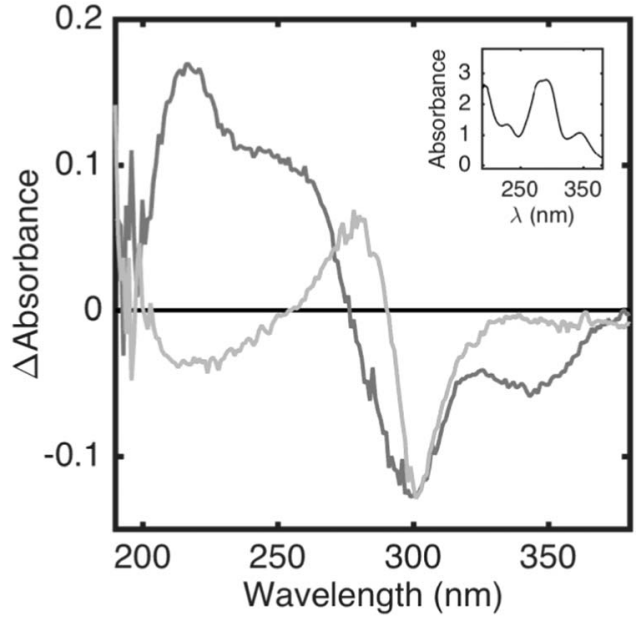

Figure 6. Change in UV absorbance of $0.001 \mathrm{M} \mathrm{V(acac})_{3}$ in $0.025 \mathrm{M}$ $\mathrm{TEABF}_{4}$-supported $\mathrm{ACN}$ after reduction at $-2.05 \mathrm{~V}$ vs. $\mathrm{Ag} / \mathrm{Ag}^{+}$for $930 \mathrm{sec}-$ onds (light gray) and oxidation at $0.65 \mathrm{~V}$ vs. $\mathrm{Ag} / \mathrm{Ag}^{+}$for 930 seconds (dark gray). The inset shows a baseline absorbance spectrum collected before the application of potential.

transfers. The combination of significant visible spectroscopic shifts and lack of change in absorbance associated with free acac ${ }^{-}$during electrolysis suggest that: exchanged electrons originate from vanadium in the $\mathrm{V}(\mathrm{acac})_{3}$ chemistry; the acac ligand in $\mathrm{V}(\mathrm{acac})_{3}$ maintains a similar atomic spacing as free $\mathrm{acac}^{-}$ions; and electrons can be added or removed from the stabilized metal center without stressing the octahedral ligand configuration.

By contrast, Figure 7 shows that the UV absorbance spectrum of $\mathrm{Cr}(\mathrm{acac})_{3}$ undergoes substantial changes as electrolysis of the complex progresses. Absorbance saturation was observed from 200-220 nm, but data outside that region is informative. As the inset in Figure 7 shows, the spectrum before electrolysis lacks the strong absorbance peak at $290 \mathrm{~nm}$ associated with the $\mathrm{acac}^{-}$moiety. This absorption spectrum in the UV region is consistent with the previous report by Barnum, with peak locations at $255 \mathrm{~nm}, 270 \mathrm{~nm}$, and $332 \mathrm{~nm}$; all three peaks also exhibit extinction coefficients, $\varepsilon$, consistent with Barnum's reported range of $\log _{10}\left(\varepsilon^{*} 1 \mathrm{cmM}\right)$ between 4.0 and $4.5 .^{34}$ The lack of absorbance at $290 \mathrm{~nm}$ in the spectrum gathered for the pristine

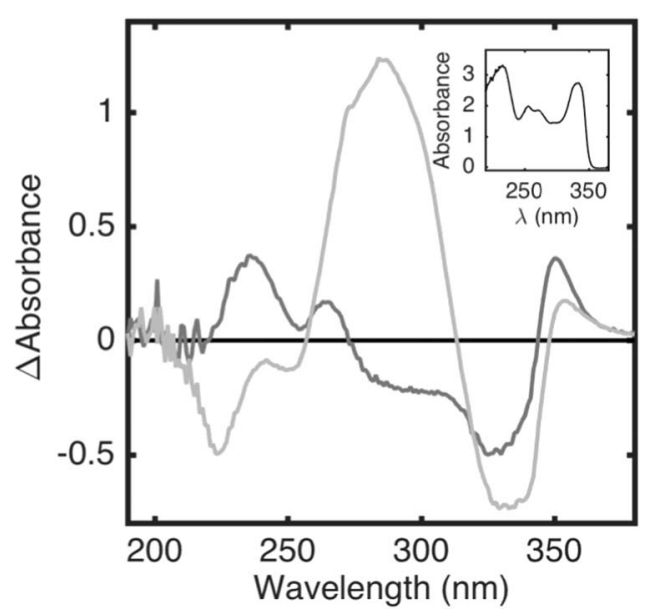

Figure 7. Change in UV absorbance of $0.001 \mathrm{M} \mathrm{Cr}(\mathrm{acac})_{3}$ in $0.025 \mathrm{M}$ $\mathrm{TEABF}_{4}$-supported $\mathrm{ACN}$ after reduction at $-2.4 \mathrm{~V}$ vs. $\mathrm{Ag} / \mathrm{Ag}^{+}$for $930 \mathrm{sec}-$

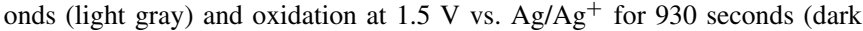
gray). The inset shows a baseline absorbance spectrum collected before the application of potential.

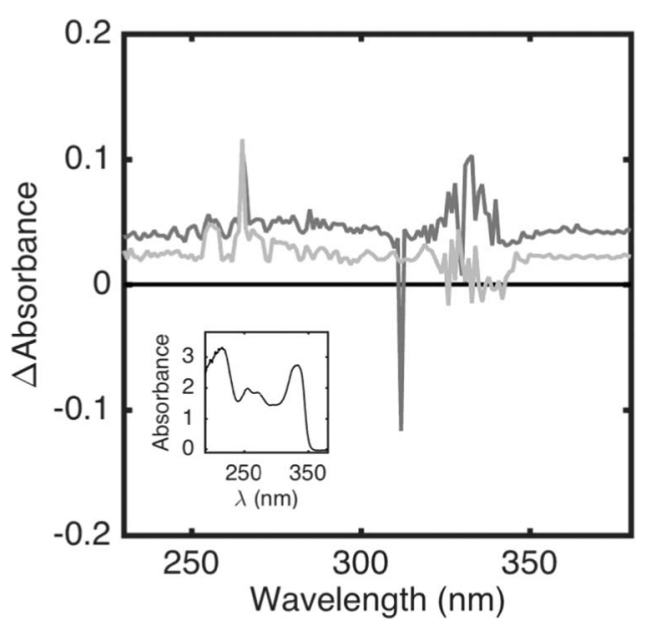

Figure 8. Change in UV absorbance of $0.001 \mathrm{M} \mathrm{Cr}(\mathrm{acac})_{3}$ in $0.025 \mathrm{M}$ $\mathrm{TEABF}_{4}$-supported $\mathrm{ACN}$ after being held at $\mathrm{OCP}\left(-0.12 \mathrm{~V}\right.$ vs. $\left.\mathrm{Ag} / \mathrm{Ag}^{+}\right)$for 930 seconds (dark gray) and when left disconnected, with reference electrode replaced by glass plug, for 930 seconds (light gray). The inset shows a baseline absorbance spectrum collected before the application of potential.

solution held at its OCP implies that the metal-ligand bond constrains the structure of the $\mathrm{acac}^{-}$ligand more in $\mathrm{Cr}(\mathrm{acac})_{3}$ than in $\mathrm{V}(\mathrm{acac})_{3}$.

Upon electrolysis, the $\mathrm{Cr}(\mathrm{acac})_{3}$ spectra change significantly for both the positive and negative couples. The reduction reaction produces a large absorbance increase from $260-310 \mathrm{~nm}$, with a peak at $290 \mathrm{~nm}$, suggesting the increased concentration of free ligand in the solution. The oxidation reaction has a lower-magnitude, mixed-polarity absorbance differential over the same window, which is consistent with reorganization after a change in redox state. Additionally, both the positive and negative couples exhibit decreased absorbance near $330 \mathrm{~nm}$. This suggests that the absorbance peak at $330 \mathrm{~nm}$ is associated with the $\mathrm{Cr}[\mathrm{III}]$ in the $\mathrm{Cr}(\mathrm{acac})_{3}$ molecule, since it decreases in both instances of conversion to different redox states. Previous studies of neutral $\mathrm{Cr}(\mathrm{acac})_{3} \mathrm{UV}$ absorption attributed the peak at $330 \mathrm{~nm}$ to the $\mathrm{Cr}[\mathrm{III}]-$ to-acac ${ }^{-}$charge-transfer band. ${ }^{34}$ The observed decrease of absorbance at $330 \mathrm{~nm}$ in the present experiments corroborates that attribution: redox reactions, which either change the valence state of $\mathrm{Cr}$ or alter the energetics of the $\mathrm{Cr}-\mathrm{acac}^{-}$bond, eliminate the absorbance at $330 \mathrm{~nm}$.

To test whether the changes in absorbance observed during both oxidation and reduction of the pristine $\mathrm{Cr}(\mathrm{acac})_{3}$ complex arose from intrusion of ambient air or reference-electrode electrolyte leaking into the working-electrode chamber, two experiments were performed, the results of which are shown in Figure 8. For one experiment, the cell's OCP, which was identified to be $-0.12 \mathrm{~V}$ vs. $\mathrm{Ag} / \mathrm{Ag}^{+}$during a galvanostatic hold at $0 \mathrm{~A}$, was applied as the chronoamperometric potential. For the other, a completely electrically disconnected cell was fabricated, in which the reference electrode was replaced by a glass rod. These time-lapse controls suggest that the influences of time held at OCP or time in contact with the reference electrode are minimal. Both the cell held at OCP and the fully disconnected cell show relatively small increases in absorbance in comparison to both the experimental noise and the increases found to accompany electrolysis.

The spectroelectrochemical observations suggest that ligand dissociation occurs during the reduction of $\mathrm{Cr}(\mathrm{acac})_{3}$. Upon reduction $\left[\mathrm{Cr}(\mathrm{acac})_{3}\right]^{-}$has a $\mathrm{d}^{4}$ electron configuration, isoelectronic with $\mathrm{Mn}(\mathrm{acac})_{3}$, which is known to have lower symmetry due to its firstorder Jahn-Teller distortion. ${ }^{37}$ This symmetry-lowering molecular distortion likely gives rise to the dissociation. Consequently, Reaction 1 is expected to produce free $\mathrm{acac}^{-}$as a reaction product. The increased complexity of this electrochemical reaction renders examination of microelectrode LSV data by the method used for $\mathrm{V}(\mathrm{acac})_{3}$ $\mathrm{LSV}^{12}$ uninformative, since the model for vanadium redox kinetics 
assumes that the first oxidation and first reduction are both singleelectron outer-sphere reactions. Additionally, the formation of acetylacetonate products during Reaction 1 suggests that its reverse involves several species, which could include the electrode, chromium coordination complexes in various forms with various redox states, and the free ligand. A true reverse reaction during discharge would require at the very least that two liquid-phase species come together at the electrode, rather than the single species that performs electron exchange in the $\mathrm{V}(\mathrm{acac})_{3}$ system.

In light of the fact that the electrolytic reduction of $\mathrm{Cr}(\mathrm{acac})_{3}$ appears to drive ligand dissociation, tethering ligands together chemically might improve reversibility of its disprortionation. As well as maintaining physical proximity of the ligand, this 'caging' of the chromium center may decrease the propensity for geometric reorganization of the complex and inhibit ligand substitutions by the solvent.

The observed spectroelectrochemical response combines with the LSV results to suggest a more refined mechanism for the cell reaction in a flow battery based on $\mathrm{Cr}(\mathrm{acac})_{3}$. Ligand dissociation in the negative couple (Reaction 1), confirmed by spectroelectrochemistry, and the $2: 3$ electron stoichiometry suggested by microelectrode LSV are consistent with the half reactions

$$
\begin{gathered}
3 \mathrm{Cr}(\mathrm{acac})_{3}+2 \mathrm{e}^{-} \rightleftharpoons \mathrm{Cr}(\mathrm{acac})_{2}^{+}+2\left[\mathrm{Cr}(\mathrm{acac})_{3}\right]^{-}+(\mathrm{acac})^{-} \\
\mathrm{Cr}(\mathrm{acac})_{3} \rightleftharpoons\left[\mathrm{Cr}(\mathrm{acac})_{3}\right]^{+}+\mathrm{e}^{-}
\end{gathered}
$$

Reaction 8 is a simple outer-sphere mechanism, but Reaction 7 involves three molecules of the neutral complex, which participate in a two-electron transfer. Although some products of Reaction 7 involve a reduced form of the complex, others leave the metal in an unchanged oxidation state with a different ligand configuration. The oxidation of ferrous acetylacetonate, where three $\mathrm{Fe}(\mathrm{acac})_{2}$ molecules combine to form two $\mathrm{Fe}(\mathrm{acac})_{3}$ molecules and a free $\mathrm{Fe}^{2+}$ cation, ${ }^{38}$ provides a precedent for a redox phenomenon like the one proposed in Reaction 7. A diffusion coefficient of $2.5 \times 10^{-5} \mathrm{~cm}^{2} \mathrm{~s}^{-1}$ can be calculated for $\mathrm{Cr}(\mathrm{acac})_{3}$ using the stoichiometry of Reaction 8 and the familiar expression for the limiting current at a disk microelectrode. Urbanczyk et al. calculated a value of $1.8 \times 10^{-5} \mathrm{~cm}^{2} \mathrm{~s}^{-1}$ in their polarographic studies of the first reduction of $\mathrm{Cr}(\mathrm{acac})_{3}$ solutions in acetonitrile, assuming a mechanism for Reaction 1 with $a=b=1 .^{15}$ If a reaction with $b / a=2 / 3$ is assumed when processing the data, consistent with Reaction 7, the diffusivity of Urbancyzyk and colleagues would become $2.7 \times 10^{-5} \mathrm{~cm}^{2} \mathrm{~s}^{-1}$, in close agreement with the present result.

Given the evidence of ligand dissociation and the mechanistic complications arising from the presence of more than one reduction product, LSV and UV-visible absorbance measurements cannot eliminate the possibility that more than one $\mathrm{acac}^{-}$ligand dissociates from the $\mathrm{Cr}[\mathrm{III}]$ center in Reaction 7. Additionally, with the observation of ligand dissociation, evidence against a disproportionation mechanism in which both the reduction and oxidation involve multiple electrons ( $a=c=1, b=2$, and $d=3$ ) is less decisive. It would still be anomalous among $\mathrm{M}(\mathrm{acac})_{3}$ complexes for $\mathrm{Cr}(\mathrm{acac})_{3}$ to support a first oxidation involving a three-electron exchange or a reduction involving two electrons, but further study is needed to corroborate the details of Reactions 7 and 8 .

Previous studies of chromous acetylacetonate, $\mathrm{Cr}(\mathrm{acac})_{2}$, report that the complex has a planar structure and is yellow in color. ${ }^{39,40}$ However, the visible absorption spectrum of the reduced $\mathrm{Cr}(\mathrm{acac})_{3}$ solution does not shift toward yellow transmittance: this suggests that if a $\left[\mathrm{Cr}(\mathrm{acac})_{2}\right]^{+}$species is present, the ligands within it retain the same geometry as in $\mathrm{Cr}(\mathrm{acac})_{3}$. It is possible that $\mathrm{acac}^{-}$, dissociated from the chromium complex as described in Reaction 7, could be replaced by two acetonitrile solvent molecules to retain the octahedral coordination of $\mathrm{Cr}$. The reduction mechanism (e.g. Reaction 7) would consequently depend strongly on solvent choice, which could explain the widely variable reduction responses of $\mathrm{Cr}(\mathrm{acac})_{3}$ observed in literature. ${ }^{13-15,17-20}$ Studies of solvent compatibility for RFB applications similar to those performed earlier with $\mathrm{V}(\mathrm{acac})_{3}{ }^{41,42}$ could therefore be fruitful, and are ongoing.
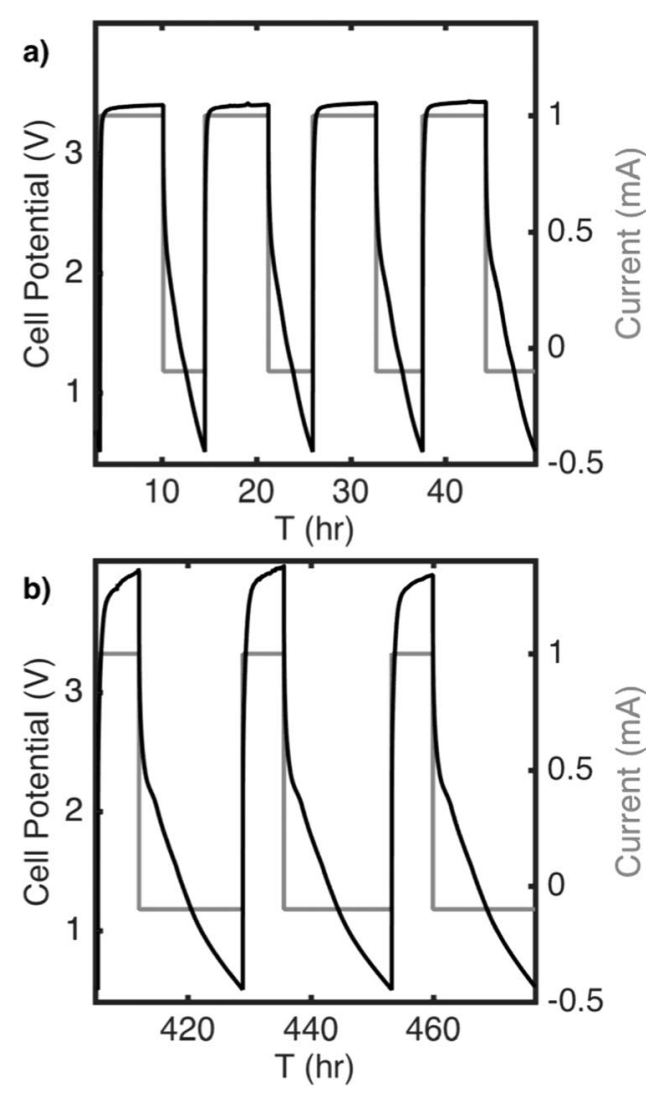

Figure 9. Charge/discharge of a cell with Celgard 4560 separator and graphite electrodes containing $0.05 \mathrm{M} \mathrm{Cr}(\mathrm{acac})_{3}$ and $0.5 \mathrm{M} \mathrm{TEABF}_{4}$ support in ACN, cycled in a glove box under Ar at 299 K. a) Cycles 1-4; b) Cycles 23-25.

\section{Charge/Discharge Testing}

As a consequence of half-Reactions 7 and 8, the overall expected cell reaction for a symmetric $\mathrm{RFB}$ based on $\mathrm{Cr}(\mathrm{acac})_{3}$ would be

$5 \mathrm{Cr}(\mathrm{acac})_{3} \rightleftharpoons 2\left[\mathrm{Cr}(\mathrm{acac})_{3}\right]^{+}+\mathrm{Cr}(\mathrm{acac})_{2}^{+}+2\left[\mathrm{Cr}(\mathrm{acac})_{3}\right]^{-}+(\mathrm{acac})^{-}$.

Ligand dissociation leads to a more complicated cell reaction for $\mathrm{Cr}(\mathrm{acac})_{3}$ than expected for simple outer-shell electron exchange for disproportion complex: charging of a flow battery using the $\mathrm{Cr}(\mathrm{acac})_{3}$ active species would entail the generation of three species in the negative electrolyte, which would have to be brought together during recharge to attain reasonable round-trip efficiency. Reaction 9 provides a lens through which to understand the charge/discharge behavior observed earlier for the symmetric nonaqueous $\mathrm{Cr}(\mathrm{acac})_{3} \mathrm{RFB}$. Previous reports ${ }^{3}$ show later cycles using a Neosepta AHA membrane, but do not illustrate the voltage response during the initial cycles of the cell. Figure 9 demonstrates initial cycles along with later, more developed cycles of a $\mathrm{Cr}(\mathrm{acac})_{3}$-based battery cell with a stagnant electrolyte, using a Celgard 4560 membrane separator. Initial cycles, shown in Figure 9a, demonstrate minimal discharge capacity. Later cycles (Figure 9b) are consistent with previous reports, ${ }^{3}$ showing increased capacity and discharge potentials beginning from $2.2 \mathrm{~V}$ and decreasing toward the $0.5 \mathrm{~V}$ cutoff. Coulombic and energy efficiencies for these cycles are $26 \%$ and $9 \%$, respectively. These efficiencies are lower than in the Neosepta-AHA-separated cells and probably owe to crossover through the porous Celgard, which is presumably far more permeable to the active species than the anion-exchange membrane. ${ }^{3}$ Despite the less selective separator, the Celgard-separated cells continue to operate after hundreds of hours. Crossover resilience is a major advantage of 'symmetric' RFB configurations; a detailed investigation of the tradeoff between separator cost and cycling efficiency for these systems is merited. 
The low efficiencies of the $\mathrm{Cr}(\mathrm{acac})_{3}$ chemistry in a stagnant 1dimensional $\mathrm{H}$-cell separated with Neosepta $\mathrm{AHA}^{3}$ or Celgard 4560 may result from the complicated nature of the cell reaction. Considering otherwise identical cells with Neosepta AHA separators, the coulombic/energy efficiencies drop from $70 \% / 35 \%$ for $\mathrm{V}(\mathrm{acac})_{3}$ to $50 \% / 22 \%$ for $\mathrm{Cr}(\mathrm{acac})_{3}{ }^{3,27}$ The cell reaction proposed here may help explain the relatively low cycling efficiency of $\mathrm{Cr}(\mathrm{acac})_{3}$. Achieving full discharge capacity would entail capturing and recombining all the Cr-containing reduction products of $\mathrm{Cr}(\mathrm{acac})_{3}$, along with free ligand. Additionally, cell Reaction 9 would explain the need for many cycles before performance achieves repeatable efficiency - the free ligand unreacted from initial cycles becomes distributed throughout the cell as time passes, facilitating the reverse reaction in later cycles and altering the Nernstian response of cell voltage. Charge/discharge experiments performed on ethylene-glycol-functionalized $\mathrm{Cr}(\mathrm{acac})_{3}$, with ethylene glycol chains bound to the acetylacetonate ligands, led to improved steady-state coulombic/energy efficiencies of 55\%/25\% at similar rates. ${ }^{43} \mathrm{~A}$ dissociation process in which the ligand diffusivity is lower, as would be the case for these bulkier ligands, may contribute to this improvement.

\section{Conclusions}

Efforts to discern the charge/discharge mechanism of the nonaqueous $\mathrm{Cr}(\mathrm{acac})_{3} \mathrm{RFB}$ using microelectrode LSV indicated a discrepancy with mechanisms proposed in prior literature. Spectroelectrochemical experiments performed with $\mathrm{V}(\mathrm{acac})_{3}$ and $\mathrm{Cr}(\mathrm{acac})_{3}$ revealed substantial differences between the redox activity of vanadium and chromium coordination complexes in nonaqueous electrolytes: vanadium appears to bind acetylacetonate such that the ligand maintains a similar absorption signature after joining the complex, whereas chromium constrains the molecular structure of acetylacetonate and eliminates its signature. Chronoamperometric reduction of $\mathrm{Cr}(\mathrm{acac})_{3}$ produced an absorbance peak in a domain of wavelengths indicative of the presence of free acetylacetonate, consistent with ligand dissociation. A new mechanism for the negative half-reaction was proposed and appears to be consistent with the charge/discharge behavior seen in a stagnant test cell.

\section{Acknowledgments}

This work was supported by the US National Science Foundation through a CAREER award, grant number 1253544. JDS thanks Dr. Emily Nelson for her valuable assistance with setting up spectroelectrochemical experiments.

\section{References}

1. J. Eyer and G. Corey, "Energy Storage for the Electrical Grid: Benefits and Market Potential Assessment Guide." Sandia Report 2010, SAND0810-2010.

2. Q. H. Liu, A. E. S. Sleightholme, A. A. Shinkle, Y. D. Li, and L. T. Thompson, "Non-aqueous vanadium acetylacetonate electrolyte for redox flow batteries." Electrochemistry Communications, 11(12), 2312 (2009).

3. Q. H. Liu, A. A. Shinkle, Y. D. Li, C. W. Monroe, L. T. Thompson, and A. E. S. Sleightholme, "Non-aqueous chromium acetylacetonate electrolyte for redox flow batteries." Electrochemistry Communications, 12(11), 1634 (2010).

4. F. R. Brushett, J. T. Vaughey, and A. N. Jansen, "An All-Organic Non-aqueous Lithium-Ion Redox Flow Battery." Advanced Energy Materials, 2(11), 1390 (2012).

5. W. Wang, W. Xu, L. Cosimbescu, D. W. Choi, L. Y. Li, and Z. G. Yang, "Anthraquinone with tailored structure for a nonaqueous metal-organic redox flow battery." Chemical Communications, 48(53), 6669 (2012)

6. M. H. Chakrabarti, R. A. W. Dryfe, and E. P. L. Roberts, "Evaluation of electrolytes for redox flow battery applications." Electrochimica Acta, 52(5), 2189 (2007).

7. T. Yamamura, Y. Shiokawa, H. Yamana, and H. Moriyama, "Electrochemical investigation of uranium $\beta$-diketonates for all-uranium redox flow battery." Electrochimica Acta, 48(1), 43 (2002)

8. Y. Matsuda, K. Tanaka, M. Okada, Y. Takasu, M. Morita, and T. Matsumurainoue, "A rechargeable redox battery utilizing ruthenium complexes with non-aqueous organic electrolyte." Journal of Applied Electrochemistry, 18(6), 909 (1988).

9. A. E. S. Sleightholme, A. A. Shinkle, Q. H. Liu, Y. D. Li, C. W. Monroe, and L. T. Thompson, "Non-aqueous manganese acetylacetonate electrolyte for redox flow batteries." Journal of Power Sources, 196(13), 5742 (2011).
10. I. V. Babich, Y. V. Plyuto, P. VanderVoort, and E. F. Vansant, "Thermal transformations of chromium acetylacetonate on silica surface." Journal of Colloid and Interface Science, 189(1), 144 (1997).

11. O. Yurchenko, K. Belikov, and N. Shevtsov, "Investigation of chromium(III) acetylacetonate as a calibration reference material for atomic absorption spectroscopy." Microchimica Acta, 160(1-2), 109 (2008).

12. A. A. Shinkle, A. E. S. Sleightholme, L. T. Thompson, and C. W. Monroe, "Electrode kinetics in non-aqueous vanadium acetylacetonate redox flow batteries. "Journal of Applied Electrochemistry, 41(10), 1191 (2011)

13. R. Landsberg, P. Janietz, and M. Prugel, "On the electrochemical reduction of some $\mathrm{Cr}(\mathrm{III})$ complexes in DMSO investigated by cyclic voltammetry." Monatshefte für Chemie, 110(4), 831 (1979).

14. B. D. Beaver, L. C. Hall, C. M. Lukehart, and L. D. Preston, "Reactions of coordinated molecules. XXVII. Cyclic voltammetry of several transition metal metallaacetylacetonate complexes." Inorg. Chim. Acta, 47, 25 (1981).

15. A. Urbanczyk, E. Debek, and M. K. Kalinowski, "Kinetics of the electroreduction of tris(acetylacetonato) chromium(iii) in nonaqueous solvents." Journal of Electroanalytical Chemistry, 389(1-2), 141 (1995).

16. R. W. Murray and L. K. Hiller, "Supporting electrolyte effects in nonaqueous electrochemistry. Coordinative relaxation reactions of reduced metal acetylacetonates in acetonitrile." Analytical Chemistry, 39(11), 1221 (1967).

17. G. Gritzner, H. Murauer, and V. Gutmann, "Polarographic and voltammetric behavior of acetylacetonato and hexafluoroacetylacetonato complexes in acetonitrile." Journal of Electroanalytical Chemistry, 101(2), 177 (1979).

18. R. Landsberg, P. Janietz, and M. Prugel, "Ligand exchange reactions of some Cr(III) complexes investigated by cyclic voltammetry." Monatshefte fur Chemie, 109(6), 1287 (1978).

19. R. F. Handy and R. L. Lintvedt, "Polarographic reduction potentials and substituent group electronic effects for a series of tris(1,3,5-diketonato)chromium(III) chelates in dimethyl sulfoxide and in dioxane-water." Inorganic Chemistry, 13(4), 893 (1974).

20. C. Tsiamis, C. C. Hadjikostas, S. Karageorgiou, and G. Manoussakis, "Ligand field, electronic and solvent effects in the non-aqueous electrochemistry of tris( $\beta$ dionato)chromium(III) chelates." Inorg. Chim. Acta, 143(1), 17 (1988)

21. R. Liu and J. Conradie, "Tris( $\beta$-diketonato)chromium(III) complexes: Effect of the $\beta$-diketonate ligand on the redox properties." Electrochimica Acta, 185, 288 (2015).

22. J. N. Burnett, L. K. Hiller, and R. W. Murray, "Supporting Electrolyte Effects in Electrochemistry: Copper and Mercury Acetylacetonates in Acetonitrile Solvent." Journal of The Electrochemical Society, 117(8), 1028 (1970).

23. S. Misumi, M. Aihara, and Y. Nonaka, "Polarography of Iron(III)- and Europium(III)Acetylacetonate Complexes in $N, N$-Dimethylformamide." Bulletin of the Chemical Society of Japan, 43(3), 774 (1970).

24. M. K. Kalinowski and A. Ćmiel, "Solvent-solute interaction. Solvent and supporting electrolyte effects in non-aqueous electrochemistry of tris(acetylacetonato)iron(III)." Inorg. Chim. Acta, 49, 179 (1981).

25. R. J. Hartley and L. R. Faulkner, "Quenching and possible coulombic complexation of the pyrene-n,n-dimethylaniline exciplex by tetraalkylammonium salts." Journal of the American Chemical Society, 107(12), 3436 (1985).

26. A. Kucernak and J. H. Jiang, "Mesoporous platinum as a catalyst for oxygen electroreduction and methanol electrooxidation." Chemical Engineering Journal, 93(1), $81(2003)$

27. A. A. Shinkle, A. E. S. Sleightholme, L. D. Griffith, L. T. Thompson, and C. W. Monroe, "Degradation mechanisms in the non-aqueous vanadium acetylacetonate redox flow battery." Journal of Power Sources, 206, 490 (2012).

28. A. Endo, Y. Hoshino, K. Hirakata, Y. Takeuchi, K. Shimizu, Y. Furushima, and H. Ikeuchi, "Electrochemistry of Tris( $\beta$-diketonato)ruthenium(III) Complexes at Platinum Electrodes in Nonaqueous Solutions and Substituent Effects on Their Reversible Half-Wave Potentials." Bulletin of the Chemical Society of Japan, 62(3), 709 (1989).

29. J. A. Bertrand, W. A. Dollase, and F. A. Cotton, "A spectroscopic study of the behavior of rhenium chlorides in molten salts." Journal of the American Chemical Society, 85 (9), 1349 (1963).

30. J. P. Lomont and C. B. Harris, "Primary photochemical dynamics of metal carbonyl dimers and clusters in solution: Insights into the results of metal-metal bond cleavage from ultrafast spectroscopic studies." Inorg. Chim. Acta, 424, 38 (2015).

31. A. M. Bond, R. L. Martin, and A. F. Masters, "Influence of oxygen and sulfur donor atoms on the electrochemistry of transition metal tris chelates." Inorganic Chemistry, 14(6), 1432 (1975).

32. T. E. Neal and R. W. Murray, "Autocatalysis of kinetic wave of acetylacetone in acetonitrile solvent." Analytical Chemistry, 42(13), 1654 (1970).

33. M. Kitamura, K. Sasaki, and H. Imai, "Studies of electrode processes of oxovanadium(iv) .4. catalytic reduction of acetylacetone coupled with cathodic reduction of "bis(acetylacetonato)oxovanadium(iv)." Bulletin of the Chemical Society of Japan, 50(12), 3199 (1977)

34. D. W. Barnum, "Electronic Absorption Spectra of Acetyl-acetonato Complexes. 1. Complexes With Trivalent Transition Metal Ions." Journal of Inorganic \& Nuclear Chemistry, 21(3-4), 221 (1961).

35. D. N. Buckley, X. Gao, R. P. Lynch, N. Quill, and M. J. Leahy, "Towards Optical Monitoring of Vanadium Redox Flow Batteries (VRFBs): An Investigation of the Underlying Spectroscopy." Journal of the Electrochemical Society, 161(4), A524 (2014).

36. I. L. Escalante-García, J. S. Wainright, L. T. Thompson, and R. F. Savinell, "Performance of a Non-Aqueous Vanadium Acetylacetonate Prototype Redox Flow Battery: Examination of Separators and Capacity Decay." Journal of The Electrochemical Society, 162(3), A363 (2015). 
37. A. Forman and L. E. Orgel, "The Jahn-Teller effect in manganic acetylacetonate." Molecular Physics, 2(4), 362 (1959).

38. W. R. Heineman, J. N. Burnett, and R. W. Murray, "Optically transparent thin-laye electrodes: studies of iron(II)-(III) acetylacetonate ligand exchange reactions in acetonitrile." Analytical Chemistry, 40(13), 1970 (1968).

39. G. Costa and A. Puxeddu, "On chromous acetylacetonate." Journal of Inorganic and Nuclear Chemistry, 8, 104 (1958).

40. F. A. Cotton, C. E. Rice, and G. W. Rice, "The crystal and molecular structures of bis(2,4-pentanedionato)chromium." Inorg. Chim. Acta , 24, 231 (1977)
41. A. A. Shinkle, T. J. Pomaville, A. E. S. Sleightholme, L. T. Thompson, and C. W. Monroe, "Solvents and supporting electrolytes for vanadium acetylacetonate flow batteries." Journal of Power Sources, 248, 1299 (2014)

42. T. Herr, J. Noack, P. Fischer, and J. Tübke, "1,3-Dioxolane, tetrahydrofuran, acetylacetone and dimethyl sulfoxide as solvents for non-aqueous vanadium acetylacetonate redox-flow-batteries." Electrochimica Acta, 113, 127 (2013).

43. J. A. Suttil, J. F. Kucharyson, I. L. Escalante-Garcia, P. J. Cabrera, B. R. James, R. F. Savinell, M. S. Sanford, and L. T. Thompson, "Metal acetylacetonate complexes for high energy density non-aqueous redox flow batteries." Journal of Materials Chemistry A, 3(15), 7929 (2015). 